\title{
Simulations of the Near-Field Transport of Radionuclides by Liquid Diffusion at Yucca Mountain -.- Comparisons with and without Emplacement Backfill
}

John J. Nitao

Earth Sciences Department

UCID--21466

Lawrence Livermore National Laboratory

DE89 013383

\section{DISCLAIMER}

This report was prepared as an accoun of work sponsored by an agency of the United States Government. Neither the United States Government nor any agency thereof, nor any of their employees, makes any warranty, express or implied, or assumes any legal liability or responsibility for the accuracy, completeness, or uselulness of any information, apparatus, product, or process disclosed, or represents that its use would not infiringe privately owned rights. Reference herein to any specific commercial product. process, or service by trade name, irademafk. manufacturer, or otherwise does not necessarily constitute or imply its endorsement, recommendation, of favoring by the United States Government or any agency thereof. The views and opinions of authors expressed herein do not necessarily state or reflect those of the United States Government or any agency thereof. 


\title{
Simulations of the Near-Field Transport of Radionuclides by Liquid Diffusion at Yucca Mountain -.- Comparisons with and without Emplacement Backfill
}

\author{
John J. Nitao \\ Earth Sciences Department \\ Lawrence Livermore National Laboratory
}

\begin{abstract}
In a previous report [Nitao, 1988b] we described the effects of hydrologic conditions on the convective and diffusive mass transfer of radionuclides. The possible set of hydrologic conditions at the Yucca Mountain repository site includes the case where groundwater recharge fluxes are sufficiently low relative to molecular diffusion in the rock so that, in the region around the waste package, the dominant mode of aqueous transpon of radionuclides is by diffusion. Although the rock at the repository level is unsaturated, a sufficient amount of pore water could form a contiguous diffusion path from the waste form wo the near-field rock if the waste is postulated 20 be in contact with the rock or emplacement backfill due to failure of the container. Future simulations will have to include conditions where the effects of convective transport in the rock are important in aqueous transport. We consider in this report simplified simulations of one-dimensional transport of radionuclides in the rock due to liquid molecular diffusion in order to determine the effects of an emplacement backfill.

Comparison of estimated release rates with and without an emplacement backfill were given in an anicle by Chambre and Pigford [1984], and these values were referenced in our previcus report Here, we have extended their calculations to include estimates using the physical parameters expected at the Yucca Mountain repository site. Our model is a simple one-dimensional treatment of diffusion in a spherically symmetric geometry that takes into account the sorbtive effects of the tuff and backfill through the use of $K_{d}$ values. This geometry rather than a cylindrical one was chosen because it is conservative in predicting higher release rates. Radioactive decay is included, and only one species al a time is treated. The dissolution of the radionuclides is assumed to be solubility-limited.

Due to the lack of experimental dala, we have used a value of one for the rock and backfill tortuosity factor, which is a conservative value from the standpoint that diffusive release rates will be overestimated. In the future, simulations using a lower value of tortwosity factor should be made in which convective transport becomes important relative to diffusion. The effect of heterogeneities, especially fractures, on the spatial variation of tonuosity and absorption have not been included in our analysis.
\end{abstract}




\section{Table of Contents}

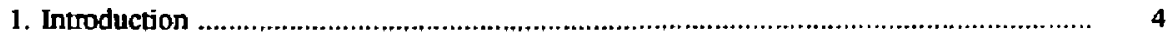

2. Mathematical Model .............................................................................................. 6

3. Verification of the Computer Model ................................................................. 7

4. Model Application ….............................................................................................. 9

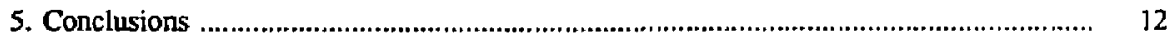

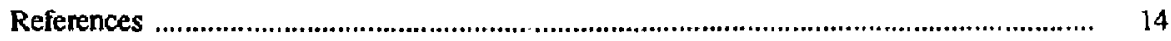

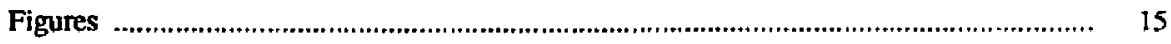

Appendix I. Discussion of Contiguous Pore Water Phase ….......................................... 22

Appendix II. Discussion of Peclet Number ............................................................ 23

\section{List of Figures}

Figure 1. Comparison Between Numerical and Analytical Solutions of Relcase Rate History

Figure 2. Comparison Between Numerical and Analytical Solutions of Steady-State Concentration Profile

Figure 3. Comparison of Concentration History at $r=0.48 \mathrm{~m}$

Figure 4. Comparison of Numerical Solution with Chambre-Pigford of Concentration History at Backfill-Tuff Interface (No Decay Case)

Figure 5. Comparison of Release Rates from Numerical Solution with ChambrtPigford (No Decay Case)

Figure 6. Comparison of Release Rates from Numerical Solution with ChambrePigford (5730 yr Half-Life Case) 
Figure 7. Release Rate for [-129, Backfill vs. No Backfill

Figure 8. Release Rate for Sr-90, Backfill vs. No Backfill

Figure 9. Steady State Concentration Profiles for Sr-90, Backfill vs. No Backfill

Figure 10. Release Rate for Pu-240, Backfill vs. No Backfill

Figure 11. Steady Slate Concentration Profiles for Pu-240, Backfill vs. No Backfill

Figure 12. Release Rate for U-234, Backfill vs. No Backfill

Figure 13. Steady State Concentration Profiles for U-234, Backfill vs. No Backfill 


\section{Introduction}

In a previous report. [Nitao, 1988b], we relied on results from Chambre and Pigford [1984] to determine the effect of an emplacement backfill on radionuclide retardation during liquid diffusive transport. The input parameters in their aricie were not specific to the Yucca Mountain repository site. We have, therefore, performed calculations using the same mathematical model but with different data. Another difference from their work is that a numerical solution method was used as opposed to an analytical one.

We discussed in this earlier report the various mechanisms of radionuclide rclease from the waste form to the surrounding rock in an unsaturated environment such as that present at the proposed high level repository sile at Yucca Mountain, Nevada. Although the rock at the repository level is unsaturated, a sufficient amount of native pore water in the rock may be present such that a contiguous diffusion path may exist in the rock and the backfill (see Appendix I for discussion). Our simulations are relevant to the scenario where the waste becomes in contact with the rock or the emplacement backfill, resulting in diffusive relcase of the radionuclides into the pore water.

Based on a calculation of the Peclet number around the waste package, which is a measure of the relative effects of convection to diffusion as a means of transport, it was found that, under some hydrologic assumptions, molecular diffusion can dominate over convection as a means of liquid transport (see Appendix II). For example, at a recharge rate at the repository level of $0.1 \mathrm{~mm} / \mathrm{yr}$ and a tortuosity factor of around unity the Peclet number is around 0.01 which, being much less than one, implies that convective transpor can be neglected relative to molecular diffusion. For some other possible values of flux and tortuosity, the Peclet number can be much greater than one, or it can be around one; in which case, convection is important, or both convection and diffusion are important, respectively.

In this report we perform some preliminary calculations on the release rates for certain radionuclides based on a simplified model of diffusive transport in the rock. Convective transport is neglected. The temperature is assumed to be close to ambient conditions after the waste package has cooled down. The calculations assume that the concentration of the radionuclide at the waste-package-10-environment interface is a constant. This last assumption is based on the assumption of solubility-limited dissolution. Due to the lack of experimental 
data we have used a value of onc for the tortuosity factor which is a conservative value from the standpoint of overestimating diffusive release rates. But in the futurc, simulations using lower values of tortuosity factor should be made, in which case, convective transport will become important relative to diffusion. The effect of spatial variations in tortuosity and sorption in the rock have also not been considercd.

The simplified mathematical models used in our simulatioris are based on solvin: the one-dimensional diffusion-decay equation in spherical coordinates for molecular diffusion, sorplion, and radioactive decay of a single aqueous specie. A $K_{d}$ coefficient is used as a simple model of radionuclide chemical adsorption. More sophisticated mathematical models may have so be developed in the future to take into account the complex hydrological and geochemical processes that may exist in the field. 


\section{Mathematical Model}

The equation describing the aqueous transport of a single species in a partially saturated porous medium through molecular diffusion is given by

$$
\frac{\partial C}{\partial t}=\frac{1}{\phi R} \nabla \cdot \tau \phi D \nabla C-\lambda C
$$

where

$$
\begin{aligned}
C \quad= & \text { aqueous phase concentration } \\
\phi \quad= & \text { porosity } \\
\tau \quad= & \text { tortuosity factor (reciprocal of tortuosity) } \\
D \quad= & \text { ionic aqueous diffusion coefficient } \\
R \quad= & \text { retardation factor, equal to }\left(1+\rho K_{d} / \phi\right) \\
& \text { where } \rho \text { is the solid density of the rock and } \\
& K_{d} \text { is the distribution coefficient } \\
\lambda \quad & \text { decay constant, equal to } \frac{\ln 2}{\text { half -life }}
\end{aligned}
$$

This equation is a special case of the equation given on page 185 of Huyacom and Pinder [1983].

The diffusive flux of the species is given by

$$
q=\tau \phi D \nabla C
$$

Assuming spherical symmetry the equation reduces to

$$
\frac{\partial C}{\partial t}=\frac{1}{\phi R} \frac{1}{r^{2}} \frac{\partial}{\partial r}\left[\tau \phi D r^{2} \frac{\partial C}{\partial r}\right]-\lambda_{C}
$$

If we assume an instantaneous rate, solubility-limited dissolution, the boundary condition at an idealized spherical source, $r=r_{0}$, is given by

$$
C\left(r=r_{0}\right)=C_{0}
$$

The solution to equation (3) is obtained numerically by discretizing the equation using finite differences. The resulting system of linear equations is solved by computer using Gaussian elimination. 


\section{Verification of the Computer Model}

We describe how the computer model was verified by first solving a simple diffusion problem which has a known elementary analylical solution and, secondly, by solving some diffusion-decay problems with more complex analylical solutions given by Chambré and Pigford [1984]. Agrecment with the krown solutions was found to be excellent.

The first verification problem is a diffusion problem for a hypothetical species with no radioactive decay. The source boundary is a sphere, and the release is into an infinite ponous medium with uniform properies and no sorbtive properties for the species. Figures 1 through 3 refer to calculations for this problem and use the following parameters for the porous medium

$$
\begin{aligned}
& \phi \quad=0.1 \\
& R=1.0 \\
& r_{0}=0.36 \mathrm{~m} \\
& D \quad=1 . \times 10^{-9} \mathrm{~m}^{2} / \mathrm{s} \\
& C_{0}=1.0
\end{aligned}
$$

The analytic solution under these assumptions is given in terms of the complementary error function by [Stakgold, 1968, p. 220]

$$
c=c_{0} \frac{r_{0}}{r} \operatorname{erfc}\left[\frac{r-r_{0}}{2 \sqrt{\ell D}}\right]
$$

where erfe is defined as

$$
\operatorname{erfc}(z)=\frac{2}{\sqrt{\pi}} \int_{z}^{\infty} \exp \left(-\tilde{s}^{2}\right) d s
$$

Figure 1 shows a comparison between the numerical and analytical release rates at the spherical source boundary. Figure 2 compares the steady state concentration profile as a function of radial distance from the center of the source. And Figure 3 is a time history of the concentration at a single point, at $r=0.48 \mathrm{~m}$. All three plots show very good agreement with the analytic and numerical solutions cssentially lying on top of one another.

In order to check the model for species with fenite half-lives, and with differing backfill and rock properties, we used the solution curves given in Chambre and Pigford [1984]. Since 
we have extracted data points from their plots visually, there will be some deviation in our graphs from their solution. The waste source in these verification cases has a radius of 0.659 $\mathrm{m}$ and a hypothetical backfill $0.30 \mathrm{~m}$ in thickness next to the waste package. Figures 4 through 5 refer to the simulation with the following parameters:

ionic diffusivity

retardation coefficient for backfill

retardation coefficient for rock

porosity of backfill

porosity of rock

half-life of species
1. $\times 10^{-9} \mathrm{~m}^{2} / \mathrm{s}$

1000 .

10.

0.20

0.01

$\infty$

And Figure 6 is for a run with the parameters:

ionic diffusivity

1. $\times 10^{-2} \mathrm{~m}^{2} / \mathrm{s}$

retardation coefficient for backfill

1000 .

retardation coefficient for rock

1000 .

porosity of backfill

0.20

porosity of rock

0.0]

half-life of species
5730. yr

Agreement is excellent considering that the solution data points were extracted visually from Chambre and Pigford's anicle. 


\section{Model Application}

We have applied the model to predict release rates based on expected parameters at Yucca Mountain including simulations that consider the effects of a Bentonite backfill.

The radionuclide species that have been considered are I-129, Sr-90, Pu-240, and U-234. This choice attempts to cover a range of retardation coefficients and half-lives. The selection was also limited by the sparsity of $K_{d}$ data available for both Bentonite backfill and Topopah tuff. It should be recognized that the values we have used are meant to be only indicative of reasonable values that might be expected in the field; more scientific woris will have to be done in order to understand the geochemical processes that are actually involved. The validity of $K_{d}$ values themselves may be questioned by some. Also, spatial variability in the geochemical properies of rock and in-situ water will also lead to differences in $K_{d}$ values. Although the assumption of solubility-limited release that we will use may not be valid for some of the above mentioned species, our simulations will, nevertheless, give an indication of the effects of a backfill.

\section{Geometric Configuration}

The radionuclide source is assumed to be spherical with a radius of 0.33 meters for the backfill case and 0.38 meters for the no-backfill case. Such a large source would correspond, for example, to a massive failure of the bottom end of a container resulting in waste form coming into contact with the tuff. From the corrosion mechanisms that are expected to occur, it is believed that such a large failure mode is untikely and that, instead, the most likely release scenario will involve pinhole-sized breaks in the container. In this latter situation with no backfill it is possible that none of the openings will even come into contact with the tuff, and no release by molecular diffusion can occur while in the backfill case release is still possible via the backfill if the waste form inside touches any water film present in the opening contacting the backfill. However, consideration of this and other possibilities is beyond the scope of this report. Instead, we are interested in the situation where without any backfill the waste form would come in contact with the tuff. In some mone likely failure modes, one may have, instead of a complete failure, a relatively small, yet significant, opening in the package. While the magnitudc of the release rates will be larger in the massive failure case than for these latter 
cases, our simulations should still give us some idea of the relative effectiveness of a backfill against having no backfill.

The borehole radius for the backfill case is taken to be $48 \mathrm{~cm}$. The bo, chole gap is therefore $15 \mathrm{~cm}$ and is packed with bentonite backfill. For the no-backfill case, the borcholc radius is $36 \mathrm{~cm}$ which leaves a $3 \mathrm{~cm}$ air gap.

\section{Backfill and Rock Properties}

The porosity of the backfill was taken 10 be 0.20 and the bulk density was $2 \mathrm{~g} / \mathrm{cc}$ based on data from [Pusch, 1980] for sodium bentonite. The tuff at the repository level was assumed to have a porosity of 0.10 and a bulk density of about $2.6 \mathrm{~g} / \mathrm{cc}$. These values are consistent with the values in NNWSI Reference Information Base [Dec. 1987, subsec. 1.3.1.2]. $K_{d}$ values were taken from various sources as described in [Nitao, 1988b].

\begin{tabular}{|l|l|l|c|}
\hline \multicolumn{3}{|c|}{ Table I. } \\
\hline isotope & half-life & $K_{d}$ (Na bentonite) & $K d_{d}$ (tufn) \\
\hline Sr-90 & $28.6 \mathrm{yr}$ & $2900 \mathrm{cc} / \mathrm{g}$ & $40 \mathrm{cc} / \mathrm{g}$ \\
\hline $\mathrm{Pu}-240$ & 6580 & 3500 & 300 \\
\hline $\mathrm{U}-234$ & $2.5 \times 10^{5}$ & 90 & 0 \\
\hline $\mathrm{I}-129$ & $1.6 \times 10^{7}$ & 0 & 0 \\
\hline
\end{tabular}

\section{Case Analyses}

Simulations were made with the isolopes in Table I. The release rates were plottei as a function of time in the following locations: waste-source-to-backfiil and backfill-to-tuff boundaries for the backfill case, and waste-source-to-tulf boundary for the no-backfill case. The release rates in the plots are normalized relative to the solubility concentration at the source which is assumed to be a constant. Plots of concentration profiles versus radial distance from the center of the spherical waste source were also made. 
Figure 7 shows the simulated release rates for I-129. The $K_{d}$ values for tuff and backfill were assumed to be zero for this species. The release rates in the backfill and no-backfill case are very close to each other; the slight difference is due to a difference in porosity of the backfill and tuff of a factor of two.

Figure 8 shows a comparison of the release rates for Sr-90, which has a thalf-life comparable to the time it takes for breakthrough to occur across the backfill if breakthrough is defined as the time that a concentration of 5 percent of that at the waste source occurs at the backfilltuff interface. The backfill-to-tuff release rate curve does not appear in the plot because the rate is always nearly zero; that is, the backfill stops practically all of the release to the borehole wall. Strontium is an element that may not be solubility-limited as we have assumed here. However, one may re-interpret the simulations in a conservative manner by assuming a very high concentration at the source. Note that in this, and in other simulations, the release rate out of the waste source and into the backfill for the backfill case is greater than from the waste source to the tuff in the no-backfill case. This effect occurs when there is a higher sorption of the radionuclide by the backfill as compared to that of tuff.

Figure 9 is a plot of the steady state concentration profile versus distance from the waste source center for Sr-90.

Figure 10 compares the release rates for Pu-240. With a backfil, the release rate into the tuff after 10000 years is a litte less than an order of magnitude lower than for the case without a backfill. Figurc 11 is a plot of the steady state spatial concentration profiles for the two cases. Note the derivative discontinuity at $\mathrm{r}=0.48 \mathrm{~m}$ for the backfill case due to the difference in porosity between the backfill and the tuff.

Figure 12 shows the release rates for U-234. At about 560 years, the rate into the tuff in the backfill case becomt: becomes slightly higher compared to the no backfill case. This difference is caused by the higher value of porosity in the backfill that we used as compared to that of the tuff. There would be hardly any difference if the pososities of the backfill and the tuff were the same. Figure 13 is a comparison of the steady state concentration profiles. Note that the concentration in the tuff $(r>48 \mathrm{~cm})$ is higher in the backfill case than in the nobackfill case, again, primarily due to the difference in porosities. 


\section{Conclusions}

In a previous repon [Nitao, 1988b], we saw that in a dry borchole environment the aqueous transfer of radionuclides from the waste form to the surrounding tuff requires that a contiguous bridge of water exist from the waste form to the rock. A necessary condition for such a bridge to exist is that a postulated break in the container be in contact with the tuff and that the break have crevices that are small enough to hold water under the high capillary suction of the tuff. Based on the current limited knowledge of the hydrological state at Yucca Mountain, the capillary suction of the rock at its native state is high enough to restrict this bridge to crevices with sizes less than a tenth of a micron, reducing the possibility of such bridges from occurring. An air gap between the container and the borehole wall would prohibit aqueous diffusive transport to the environment. This conclusion assumes that the container is kept from contact with the tuff by the use of stands. On the other hand, a backfill placed between the container and the borehole wall would provide an avenue for diffusive transport to the tuff.

Our simulations of the no-backfill case are pertinent only to the, perhaps unlikely, scenario that a coniguous bridge of liquid water is sustained from the waste form to the tuff. For the backfill case, it is assumed that such a bridge exists from the waste form to the backfill. Note that our simulations and the resulting release rates do not take into account the lower probability of a contiguous diffusion path occurring in the no-backfill case than in the backfill case. Hence, the rates are not expected values from a probabilistic standpoint since they do not account for the probability of the sequence of events that lead to the given release scenario. The comparisons we will make with respect to release rates should be viewed in this light; they refer only to release rates under the assumption that cquivalent conditions for diffusive transport exist, but without regard to the actual statistical expectation values that these conditions occur. With these qualifications in mind, some of the conclusions are:

1. As expected, isotopes such as those of iodine, that have long half-lives and are not significantly sorted by tuff or Bentonite backfill, will show litule difference in rclease rates between the backfill and no-backfill cases.

2. Some isotopes such as Pu-240 have their release rates significantly reduced by a Bentonjte backfill. 
3. Some isotopes such as U-234 will have an initial reduction in the release rate due to the backfill but will settle down to a steady state ratc that is about the same as for the case without a backfill.

4. For isotopes that are more sorbed by the backfill than by tuff, the presence of a backfill against a container openirig will significantly increase the rate of transport out of the container as compared to the case where tuff is against the opening. However, subsequent diffusive transpon from the backfill to the tuff is less or about the same in some cases. Steady-state concentration profiles in the tuff for species that escape the backfill barrier before decaying are in some cases significantly lower with a backfill and in other cases are higher but not by more than 20 percent in the cases considered. 


\section{References}

Chambre, P.L., and Pigford, T.H., Prediction of Waste Performance in a Geologic Repository, Mat. Res. Soc. Symp. Proc., Elsevier Science Pub. Co., vol. 26, pp. $985-1008$ (1984).

Dullien, F.A.L., Porous Media, Fluid Transport and Pore Strucsure, Academic Press (1979).

Huyacom, P.S. and Pinder, G.F., Computational Methods in Subsurface Flow, Academic Press, (1983).

Montazer, P. and Wilson, W., Conceptual Hydrologic Model of Flow in the Unsaturated Zone, Yucca Mountain, Nevada, Water Resources Investigations, Repon 84-4345, Uniled Statcs Geological Survey, Denver, Colorado, (1984).

Nitao, J.J., Interdept. Memo to J. Kass with an attached report: "Transport of Water in Bentonite Backfill", (Feb. 9, 1988a).

Nitao, J.J., Interdept. Memo to J. Kass with an altached report: "The Effect of Hydrology on the Mass Transfer of Aqueous Species to the Near Field Environment at Yucca Mountain", (March 14, 1988b).

NNWSI, The NNWSI Project Reference Information Base, compiled by F.J. Schelling, Version 02.001, SLTR87-6001, (May 1987).

NNWSI, The NNWSI Project Reference Information Base, Version 03.001, (Dec. 1987).

Peters, R.R., Klavetter, E.A., Hall, I.J., Blair, S.C., Heller, P.R., and Gee, G.W., Fracture and Matrix Hydrologic Characteristics of Tuffaceous Materials from Yucca Mountain, Nye County, Nevada, Sandia National Laboratories report no. SAND84-1471, (Dcc. 1984).

Pigford, T.H. (chairman), A Study of the Isolation System for Geological Disposal of Radioactive Wastes, National Academy Press (1983).

Pusch, R., Water Uptake, Migration and Swelling Characteristics of Unsaturated and Saturated. Highly Compacted Bentonite, SKBF KBS Tech. Report No. 80-11, Sweden (1980).

Stakgold, I., Boundary Value Problems of Mathematical Physics, Vol. II, Macmillin, (1968). 


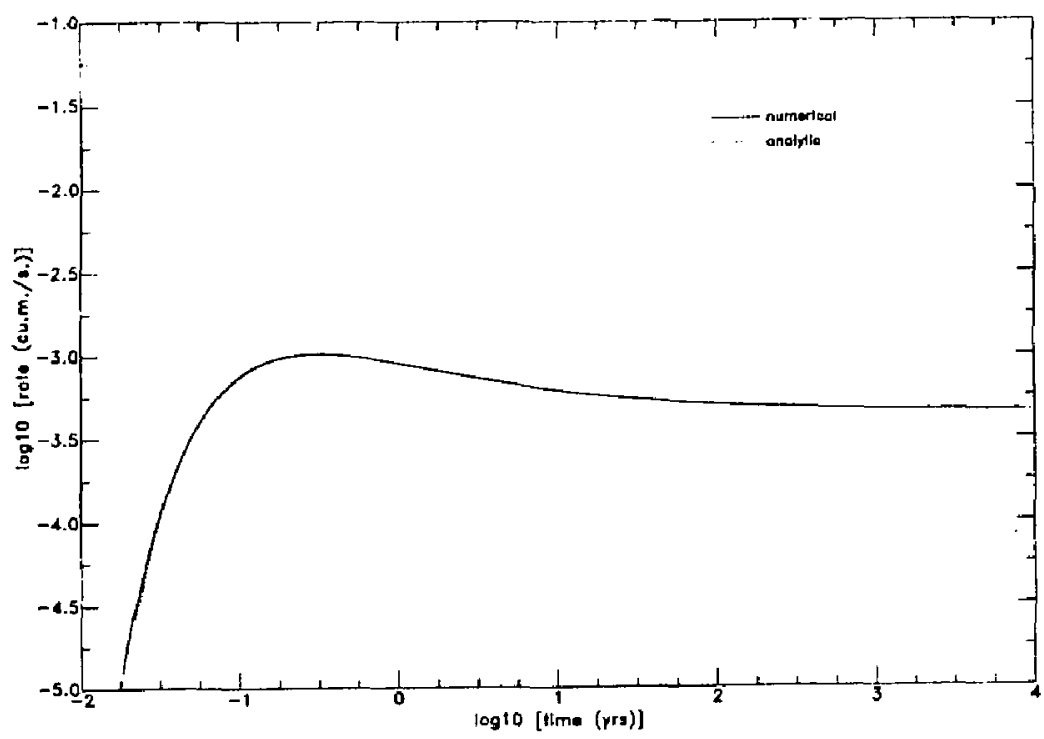

Figure 1. Comparison Between Numerical and Analytical Solutions of Release Rate History

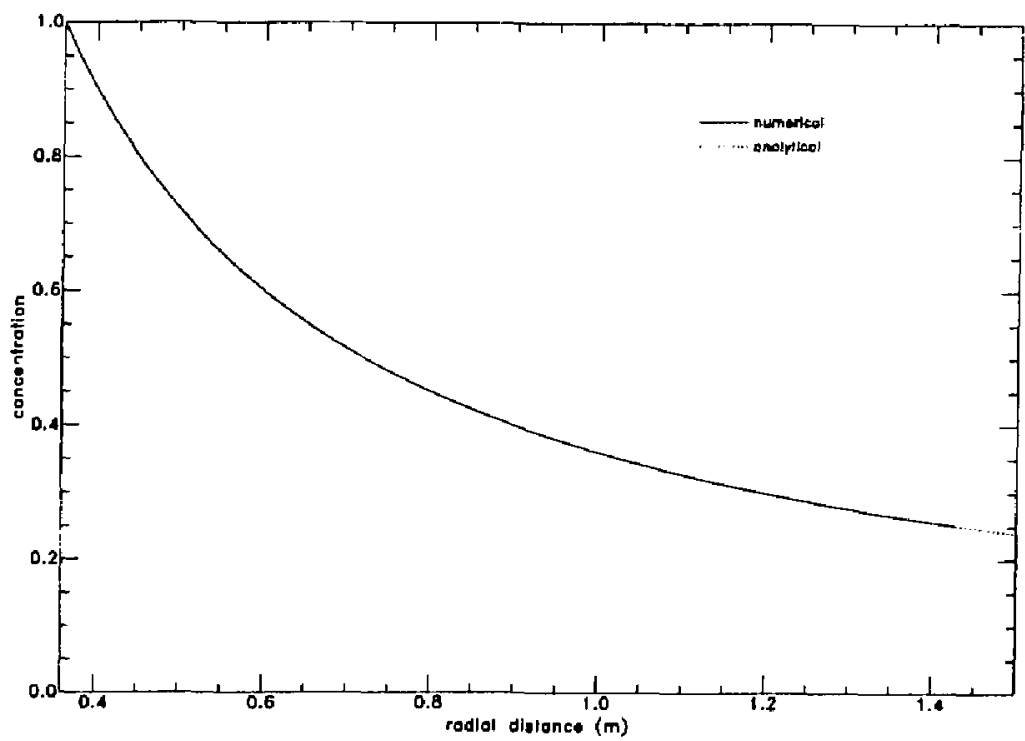

Figure 2. Comparison Between Numerical and Analytical Solutions of Steady-State Concentration Profile 


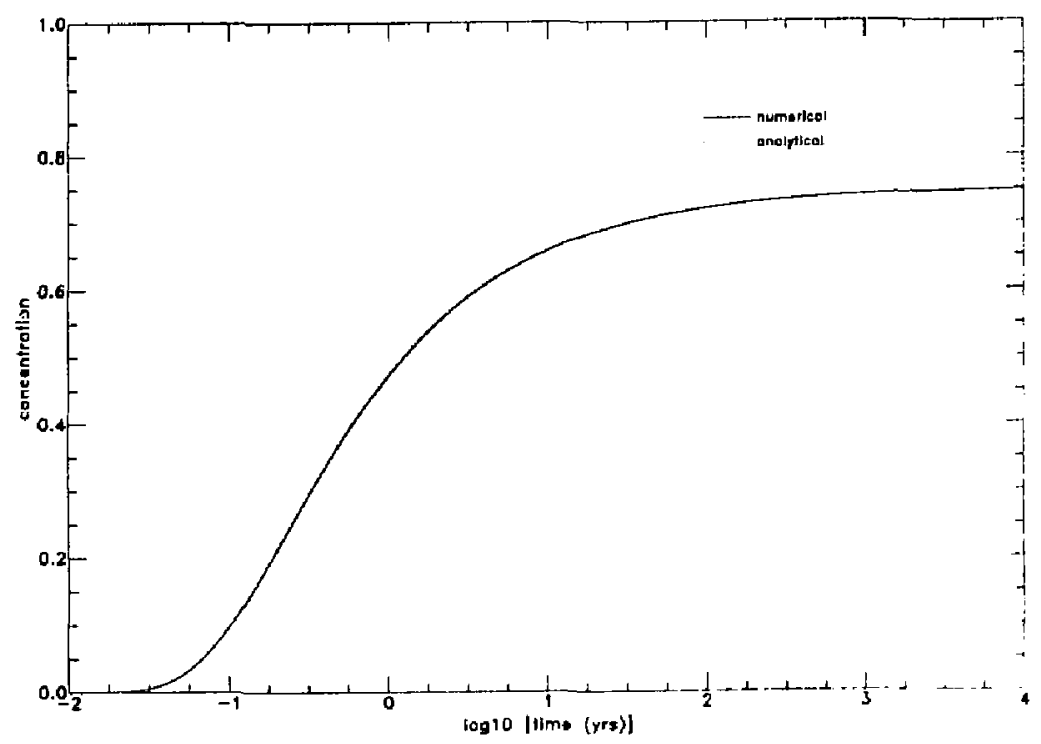

Figure 3. Comparison of Concentration History at $r=0.48 \mathrm{~m}$

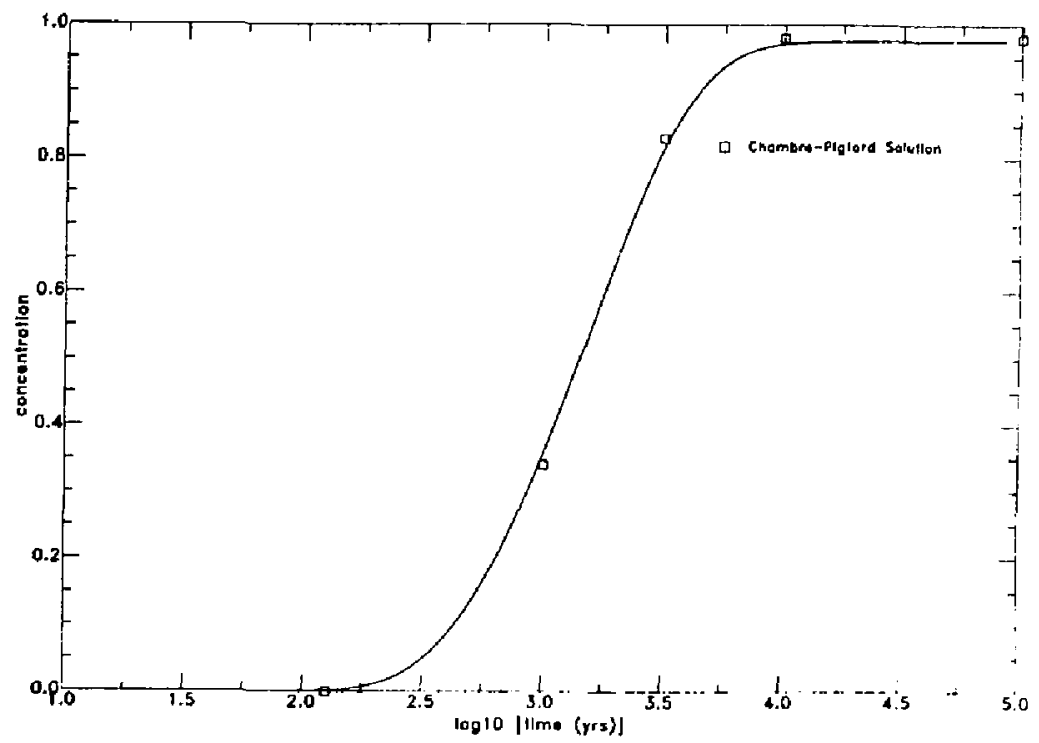

Figure 4. Comparison of Numerical Solution with Chambré-Pigliord of Concentration History at Backfill-Tuff Interface (No Decay Casse) 


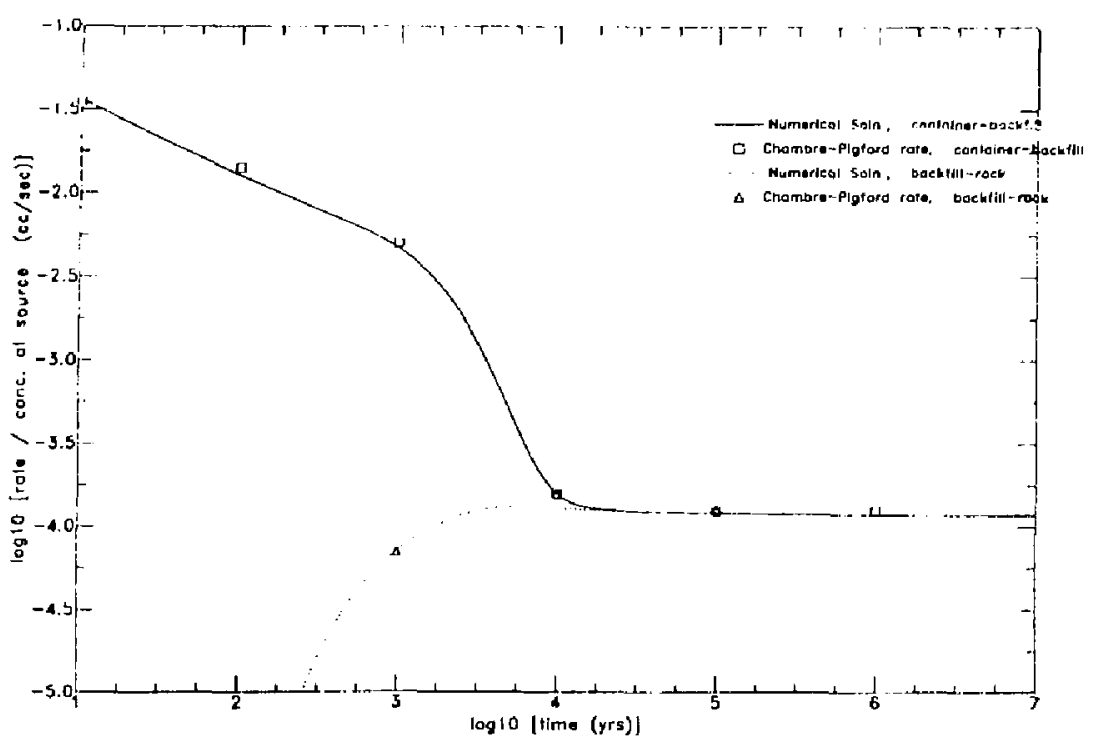

Figure 5. Compizitison of Release Rates from Numerical Solution with Chambré-Pigford (No Decay Case)

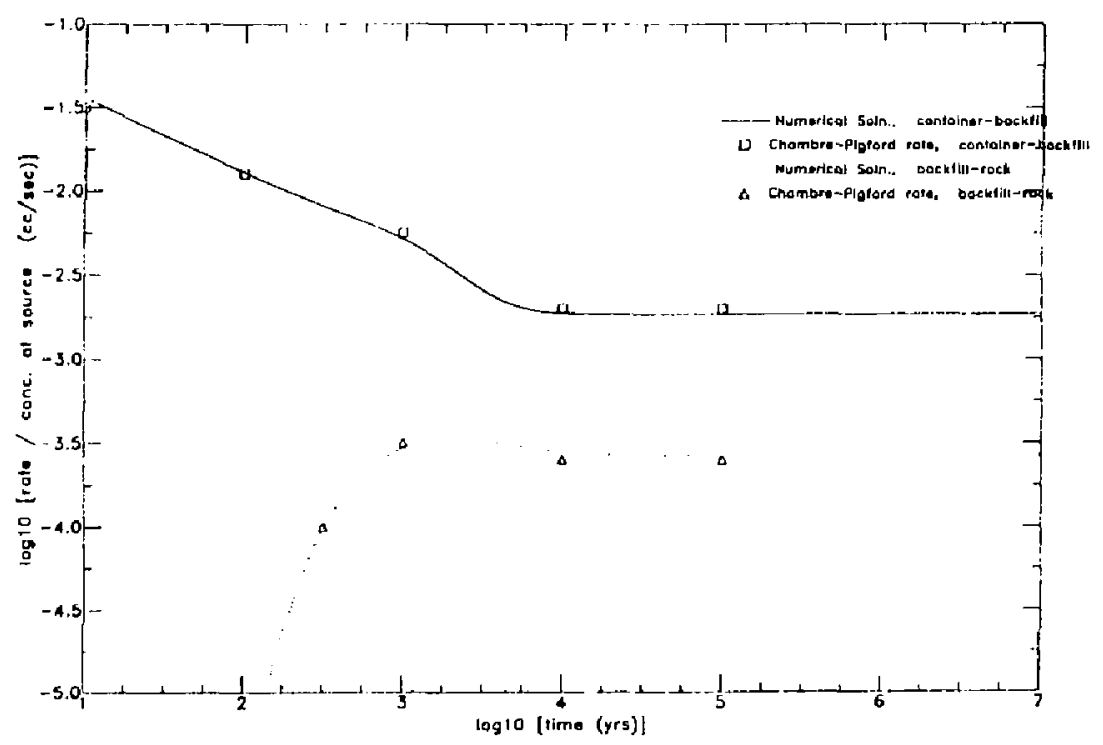

Figure 6. Comparison of Release Rates from Numerical Solution with Chambré-Pigford ( 5730 yr Half-Life Case) 


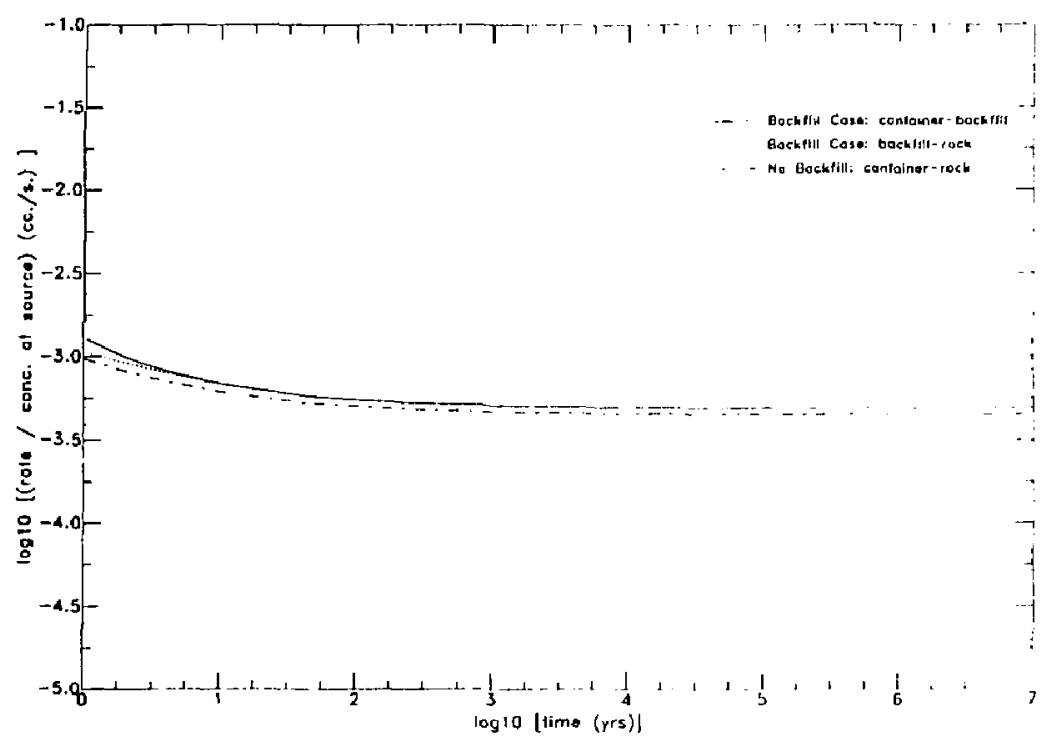

Figure 7. Release Rate for I-129, Backfill vs. No Backfill

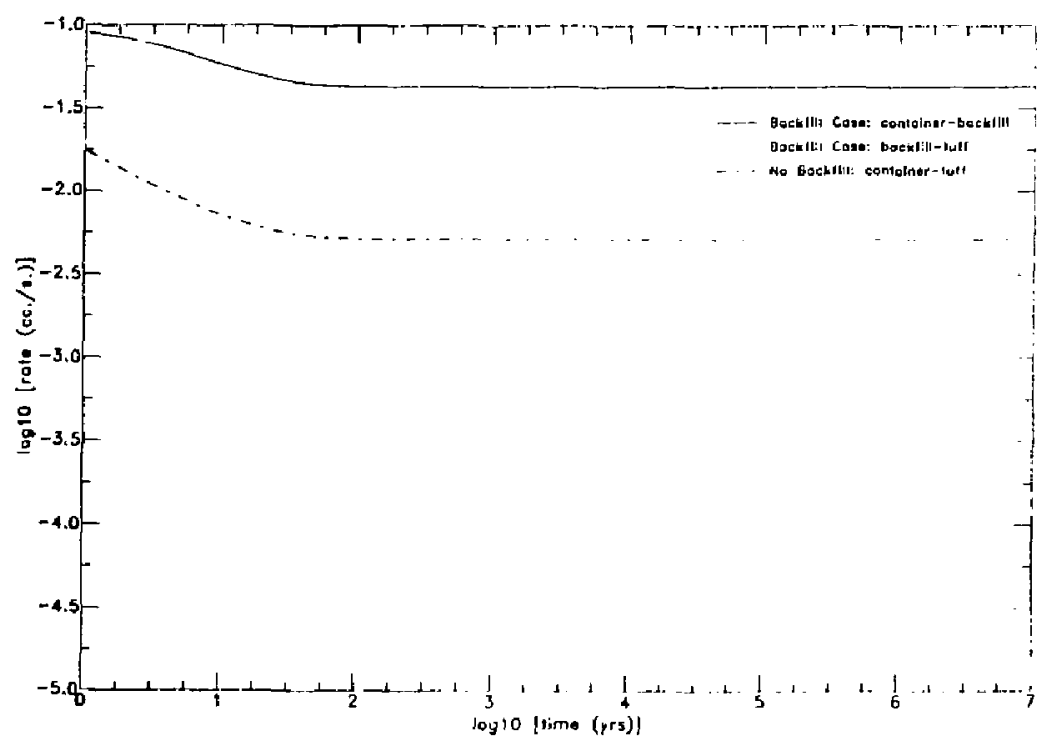

Figure 8. Release Rute for Sr-90, Backfill vs. No Backfill 


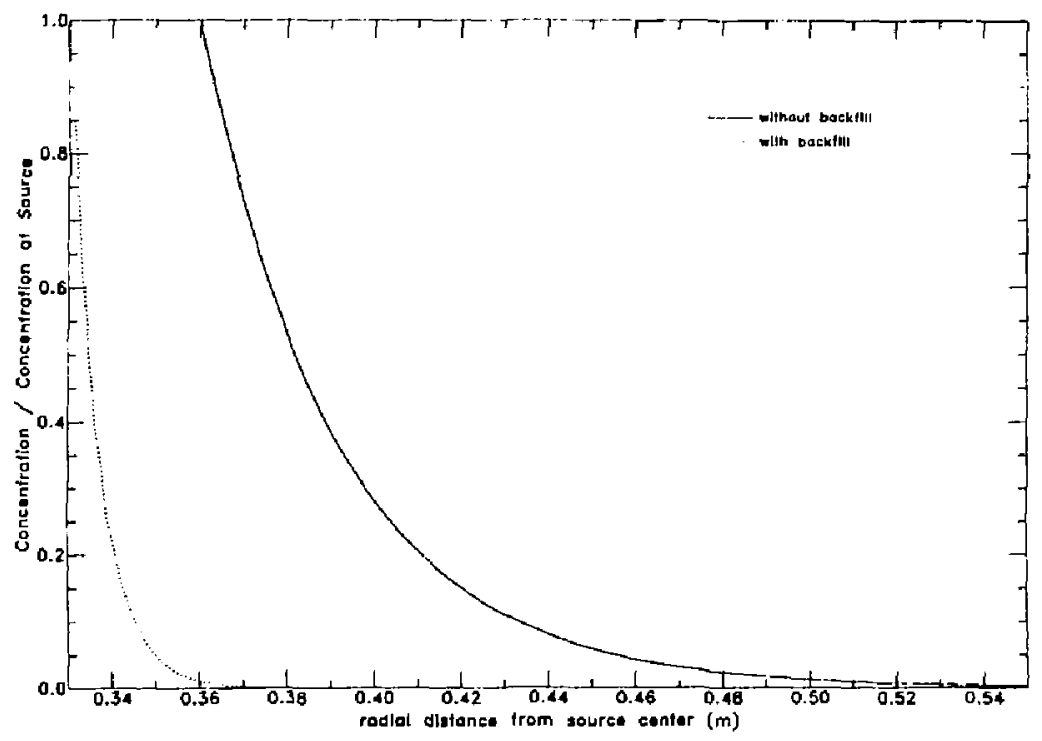

Figure 9. S1eady State Concentration Profiles for Sr-90, Rackfill vs. No Backfill

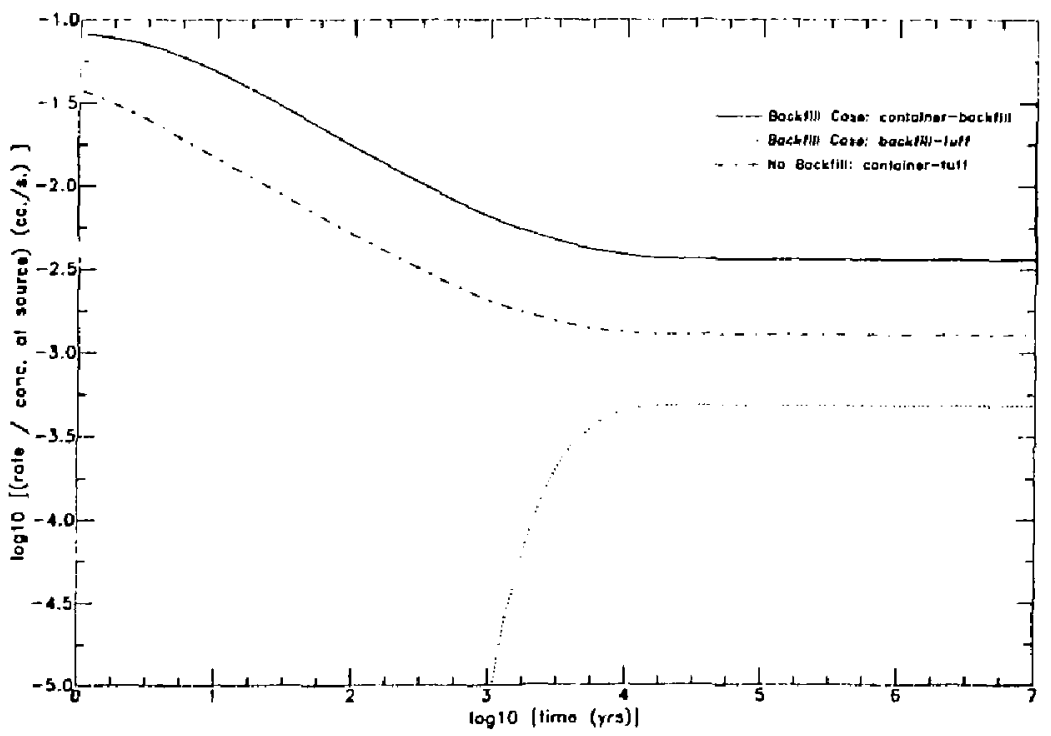

Figure 10. Release Rate for Pu-240, Backfill vs. No Backfill 


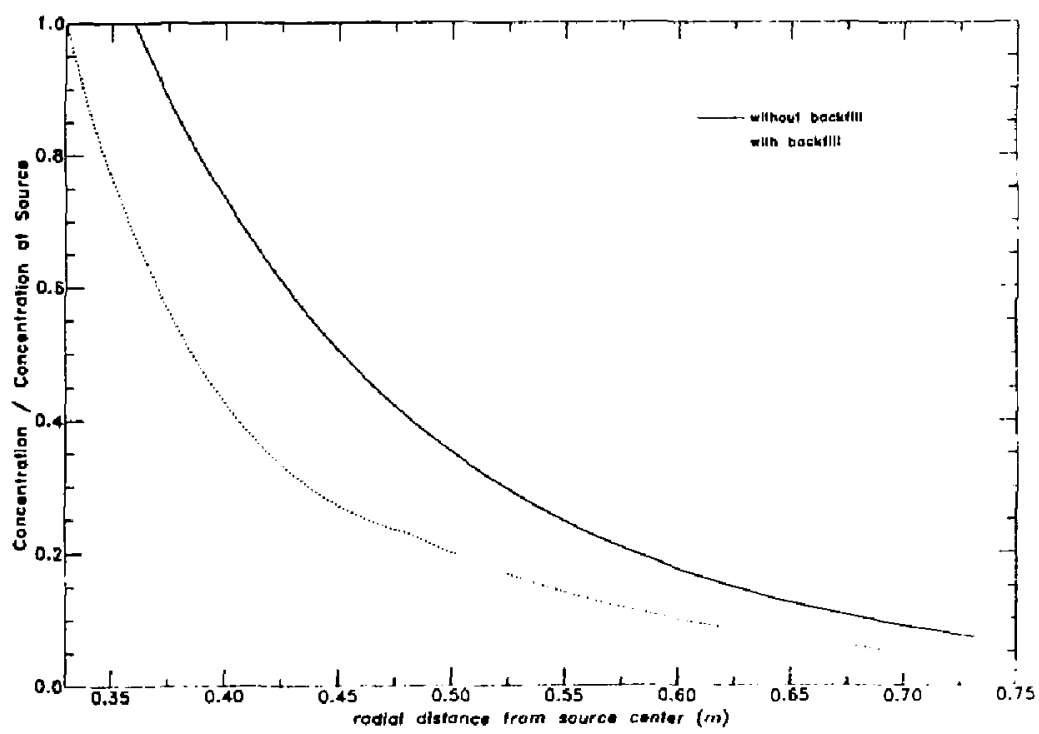

Figure 11. Steady State Concentration Profiles for Pu-240, 1kacktill vs. No 13ackifill

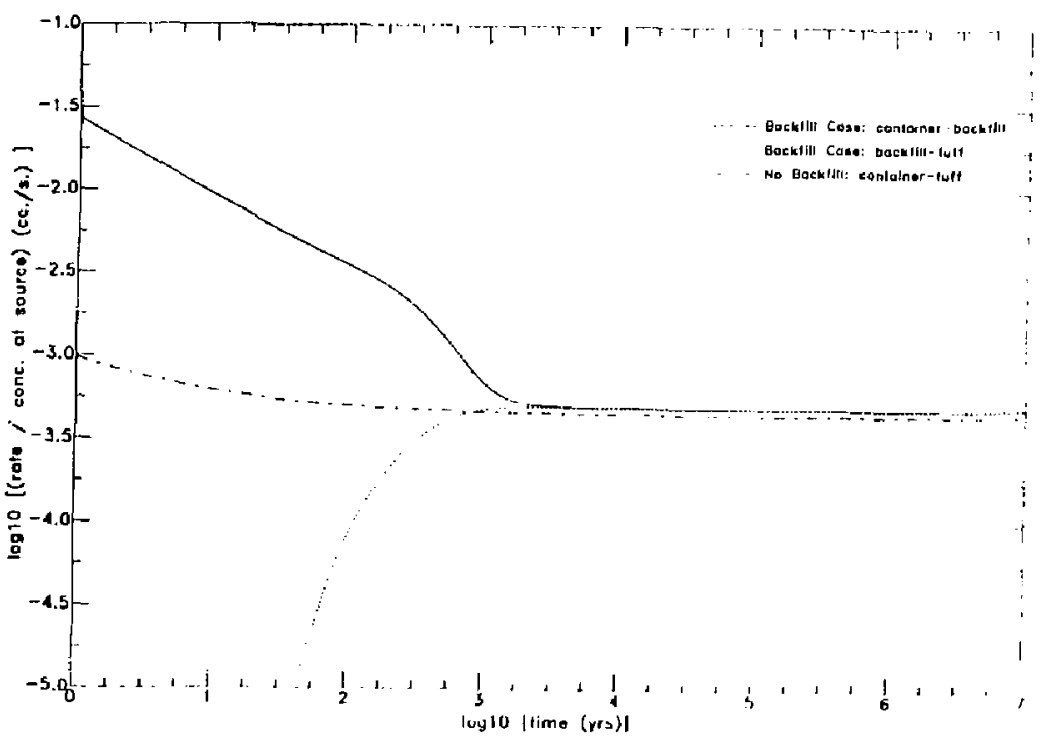

Figure 12. Release Rate for I-234, Backfill vs. No Back(ill 


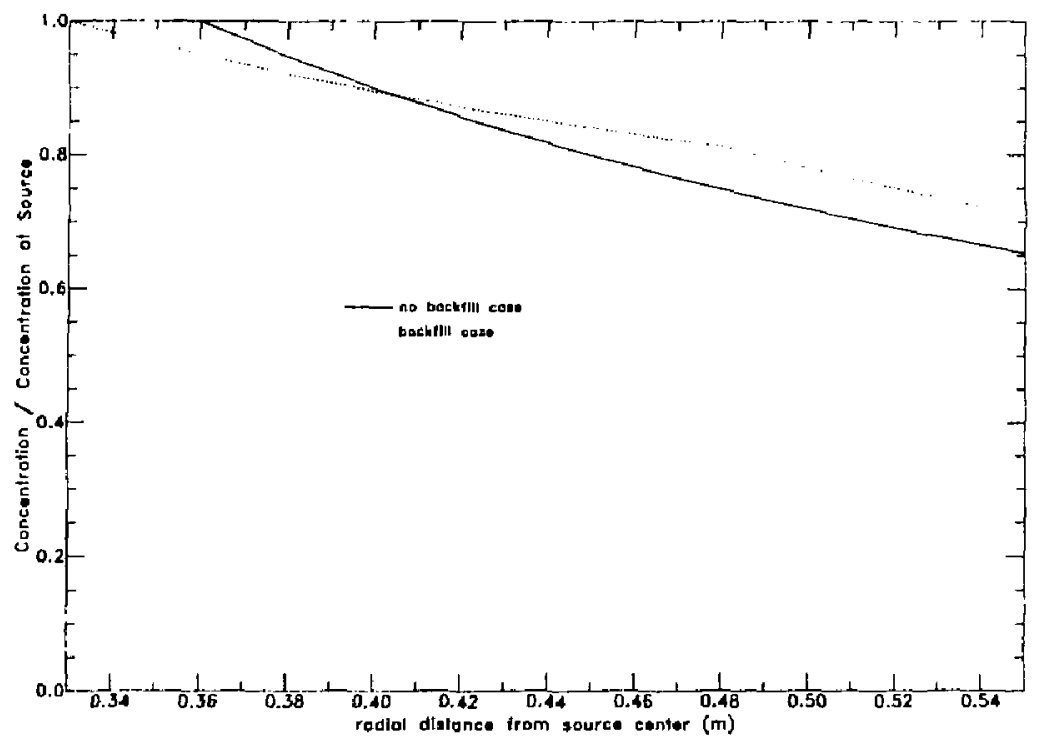

Figure 13. Steady State Concentration Profiles for U-234, Backfill vs. No Backfill 


\section{Appendix I. Discussion of Coníiguous Pore Water Phase}

In this report we have assumed that there is sufficient pore water in the tuff and bentonite backfill that a contiguous pathway can occur for transpont by liquid diffusion. Current conceptual hydrological models indicate the possibility of a non-zero recharge rate at the repository herizon [Montazer and Wilson, 1984]. Under this scenario the rock must be permeable to liquid water at its curnent native saturation saluration and, hence, has liquid saturation above the residual value. From unsaturated flow theory there must be a contiguous phase of water in the tuff [Dullien, 1979, p. 32]. The bentonite, because of its sorbtion properties, would also have a contiguous phase of water [Pusch, 1980] in equilibrium suction with the tuff. Liquid diffusion of solutes through the backfill and tuff is, therefore, a possible mechanism of transport that must be considered. 


\section{Appendix II. Discussion of Peclet Number}

Although the value of physical parameters such as recharge llux and rock tortuosity are, at this time, unknown or uncertain, it is instnctive to see what possible values of Peclet number may be encountercd around the waste package. The Peclet number $P e$ is given in Bear $[1972$, p. 600$]$ and is a measure of the relative imponance of convective to diffusive effects of transpon in porous media. It is defined as

$$
P e=\frac{L U}{t D}
$$

Here,

$$
\begin{aligned}
& L \quad=\text { 'laracteristic length } \\
& U \quad=\text { iunvective pore velocity } \\
& D \quad=\text { ionic diffusion coefficient (without retardation) } \\
& \tau \quad=\text { tortuosity factor }
\end{aligned}
$$

In our problem we are interested in the relative importance of diffusion and convection in the vicinity of the waste package. We, therefore, take the characteristic length to be the waste package radius [Chambré and Pigford, 1984]. (Note: if the far-field were being modeled, the characteristic length would be much larger so that the resulting Peclet number; would be greater and convection would become more important.)

Simulations performed by Wang and Narasimhan [1986] indicate that a likely hydmological condition at the repository horizon is for the water to flow entirely in the matrix with no flow present in the fractures. The recharge rate flowing through the Topopah Spring unit has been estimated to be at most $1 \mathrm{~mm} / \mathrm{yr}$ [Montazer and Wilson, 1984]. Taking this value as the pore velocity of the water flowing in the matrix around the waste package, the pore velocity $U$ in the matrix is estimated to be about $3.2 \times 10^{-10} \mathrm{~m} / \mathrm{s}$, which is obtained by dividing the recharge rate by the value of rock porosity equal to 0.10 . The non-retarded coefficient for molecular diffusion used in the text is $D=1 \times 10^{-9} \mathrm{~m}^{2} / \mathrm{s}$. With the radius of the waste package of $0.38 \mathrm{~m}$ as the characteristic length $L$, we obtain a Peclet number of about $P e=0.1$ for a tortuosity factor of $\tau \approx 1, P e=1.0$ for $\tau=0.1$, and $P e=10.0$ for $\tau \approx 0.01$. For a lower recharge flux of $0.1 \mathrm{~mm} / \mathrm{yr}$, the correponding values of $P e$ would, of course, be an order of magnitude less. The significance of the Peclet number is that when it is much greater than unity, convective transport dominates over diffusion. The reverse is true when $P e$ is much less than unity. 


$$
.24-
$$

When $P e$ is around unity, both diffusion and convection are important. We see, then, that all three of these possiblities are within the range of our postulated input parameters. However, in this report we analyze only those cases when transpor is primarily by diffusion, i.c., when $P e \ll 1$. Since the tortuosity factor for Topopah tuff is not known at this time. we have arbitrarily used a value of unity. If in the future, the value is shown to be much smalle?, the effect on the simulation results is to decrease the transpor velocity by diffusion in the tuff. A similar effect will occur in the backfill, as well, if the tortuosity there is also significantly less than one. 